Please quote as: Kolloch, M. \& Dellermann, D. (2017): Digital Innovation in the Energy Industry: The Impact of Controversies on the Evolution of Innovation Ecosystems. In: Technological Forecasting \& Social Change. 



\title{
Digital innovation in the energy industry: The impact of controversies on the evolution of innovation ecosystems
}

\author{
Michael Kolloch ${ }^{\mathrm{a}, *}$, Dominik Dellermann ${ }^{\mathrm{b}}$ \\ ${ }^{a}$ Chair of Innovation Management, University of Bamberg, Kärntenstrasse 7, 96052 Bamberg, Germany \\ b Research Center for IT Design (ITeG), University of Kassel, Chair for Information Systems, Pfannkuchstrasse 1, 34119 Kassel, Germany
}

\section{A R T I C L E I N F O}

\section{Article history:}

Received 30 November 2015

Received in revised form 10 March 2017

Accepted 26 March 2017

Available online $\mathrm{xxxx}$

\section{Keywords:}

Innovation ecosystem

Virtual power plant

Digital innovation

Digitization

Co-evolution

Energy industry

Actor-network theory

\begin{abstract}
A B S T R A C T
The concept of innovation ecosystems gained significant importance in academic research on strategy and practice over the last years. The emergence of the Internet of Things is disrupting industries and setting the ecosystem in the focus of innovation. Even traditional analog industries, like the energy industry, are under pressure to foster and manage ecosystems during their innovation efforts. Thus, the energy industry represents an appropriate setting for examining the evolution of an innovation ecosystem under the empirical lens of controversies, which describe the challenges of the status quo and is congruent with previous research on dialectical inquiries as source of innovation dynamics. For the purpose of this paper, the Actor-network theory (ANT) is regarded as an appropriate tool since it allows researchers to analyze how actors interact due to their specific interests with each other and thus configure the ecosystem in its base. ANT further enlarges the perspective of handling actors, while it involves not only human but also non-human actors (i.e. technologies). This is a valuable and necessary feature while dealing with digital innovations such as virtual power plants (VPP). By analyzing three how distinctive typologies, their mechanisms as well as their pathways of controversies affect the innovation ecosystem of VPPs and the evolution of the technological components of the innovation, this interaction between human and non-human actors is highlighted. In consequence, our research emphasizes the significance of involving nonhuman actors into managerial strategies and the role they inherit for the evolution of ecosystems. Furthermore, the present research reveals that controversies are not only a moderating factor but also a constitutional one for the coevolution of the ecosystem as well as the innovation itself especially during the forming phases. With respect to recent research of the management of digital innovation, this paper contributes to a better understanding of managerial challenges associated with digital innovation and their respective ecosystems.
\end{abstract}

(c) 2017 Elsevier Inc. All rights reserved.

\section{Introduction}

The emergence of the Internet-of-Things (IoT), creates a technological network of connectivity with self-configuring capabilities that are enabled by standardized and interoperable formats and connecting heterogeneous digitized objects via the internet (Atzori et al., 2010). Digital technology therefore is combining digital and physical components into novel value propositions. Furthermore, ubiquitous computing enables the interconnection of multiple devices (Yoo et al., 2010).

Along with this digitization of technology, the organizing logic of innovation is changing (Yoo et al., 2010). Schumpeter (1942) model of the lone entrepreneur that brings a certain value proposition to the market has to be rethought, as innovation are increasingly created in networks

\footnotetext{
* Corresponding author.

E-mail addresses: michael.kolloch@uni-bamberg.de (M. Kolloch), Dellermann@uni-kassel.de (D. Dellermann).

URL: http://www.uni-bamberg.de/bwl-inno/ (M. Kolloch), (D. Dellermann).
}

(i.e. ecosystems) of produces, users, complementors and several other institutions that create a social system consisting of multiple and heterogeneous actors (Adner, 2006; Moore, 1993). The high level of openness in innovation makes firms more dependent on each other as well as dynamics within the firm's environment (Adner and Kapoor, 2010; Battistella et al., 2013; Chesbrough, 2006). Therefore, innovation ecosystems are an ensemble of interdependent and heterogeneous actors (e.g. suppliers, distributors, competitors, customers, government, and other institutions) (Moore, 1993; Teece, 2007) that emerge around an innovation (i.e. a technological network) and are dynamic and steadily evolving (Iansiti and Levien, 2004).

Understanding how such ecosystems evolve over time is becoming critically important for many firms. Hence, research on ecosystem evolution gains increasing attention (e.g. Henfridsson and Bygstad, 2013). Drawing on the metaphor of a biological ecosystem, one suitable way to explain the path-dependent and frequently chaotic dynamics within such a system is Darwin's (1859) notion of evolution and co-evolution. While evolution describes the change of a system over time on a more 
holistic level, co-evolution explicitly focuses on the interaction between entities within a system that creates conflict or cooperation and therefore creates dynamics.

One aspect that has not been considered by research on ecosystem dynamics is an integrated view on how such interaction between both, technological and human entities in an ecosystem affect the relationships among them and influence the dynamics of an innovation ecosystem. However, integrating the technological as well as the social perspective is required to gain a deeper understanding of the dynamics of innovation ecosystems.

We therefore argue that Actor Network Theory (ANT) is a suitable theoretical lens (Callon, 1986; Latour, 1990) for analyzing an innovation ecosystem as network of human (e.g. organizations) and non-human (e.g. technological) actors. In particular, the dynamics of an ecosystem are defined as a socio-technological process in which various organizations translate and inscribe their interests into a technology, creating an evolving network of human and non-human actors (Henfridsson and Bygstad, 2013). Controversies are situations in which formerly fixed ideas are challenged and contradict the status quo (Latour, 2005; Venturini, 2010). Such changes in the status quo of a socio-technological system frequently lead to ripple effects, which result in an overall system's evolution. In the sense of ANT this can be positive controversies such as the emergence of novel ideas or technologies or negative like in the sense of conflicts. This argumentation is in line with previous research that highlighted the role of dialectic objectives and conflicts in organization or groups as source of innovative outcomes (Harvey, 2014). However, this research was neither focusing on the interorganizational level of ecosystems nor did it examine the crucial role of technology in such settings. Therefore, the concept of controversies in socio-technological actor networks are a suitable mechanism to explain ecosystem dynamics

In order to analyze the impact of such controversies on ecosystem evolution, we addressed several key questions: What are typologies of controversies within the innovation ecosystem? How do they affect the dynamics of ecosystem? Moreover, what is the underlying logic of the evolution process shaped by controversies?

For this purpose, we organized the paper as follows. The upcoming sections review present work on the emergence and characteristics of digital ecosystems and our conceptual framework based on ANT. We then argue for virtual power plants (VPPs) as suitable objects for examining digital ecosystems. In order to investigate the impact of controversies on digital innovation ecosystems, we apply a case study approach examining a project of setting up a VPP within the German energy industry. A discussion of the results derived from the case analysis draws the contribution to the mechanisms of controversies on the evolution of the ecosystem. The contribution and the limitations of the paper are highlighted in the concluding section.

\section{The emergence of digital ecosystems as new organizing logic for innovation}

As digital technology is combining digital and physical components into new value propositions, firms can no longer rely on enhancing features and the quality of their products by solely focusing on their individual innovation efforts. Digital disruption in various traditional industries requires the blurring of industry boundaries and converging knowledge bases. Such convergence brings together previously separated user experiences (e.g. adding mobile internet), physical and digital components (e.g. smart products) and previously separated industries (e.g. software and hardware industry) (Yoo et al., 2010).

In general, the properties of digital technology implicate a layered architecture (Adomavicius et al., 2008), which is a specific functional design hierarchy that initiates the modular design of digital innovation (Baldwin and Clark, 2000). This allows an effective division of labor among different actors during the design and production of complex systems (Sosa et al., 2004; Staudenmayer et al., 2005). Thus, pervasive digital technology can be seen as an enabler of new market dynamics as well as increased exchange of specialized competences (e.g. knowledge and skills) between heterogeneous actors in complex network structures (Yoo et al., 2010). The modularity of digital innovation is therefore changing the traditional value chain into value networks and fundamentally reshaping the traditional innovation logic (Garud and Kumaraswamy, 1993; Sosa et al., 2004). In particular, the combinable developmental process of novel digital technology explains how components interact with other components and reshape an ecosystem of human and non-human actors.

The concept of such ecosystem helps to analyze interdependencies more explicitly (Adner and Kapoor, 2010; Iansiti and Levien, 2004; Moore, 1993). Innovation ecosystems are defined as a "[...] loosely interconnected network of companies and other entities that coevolve capabilities around a shared set of technologies, knowledge, or skills, and work cooperatively and competitively to develop new products and services [...]." (Nambisan and Baron, 2013:1071).

Organizations increasingly participate in ecosystems to capitalize on knowledge outside the boundaries of the single firm (Chesbrough, 2006; Simard and West, 2006). The companies' single innovation efforts therefore reciprocally influence each other making the relationships among the actors of the ecosystem central to its success (Iansiti and Levien, 2004). Digital ecosystems are not homogenous constructs but include different actors with different kinds of relations and variable strength of ties among them (Teece, 2007). Vice versa, an ecosystem is not a stable construct but a dynamic and steadily evolving entity, which is changed by the relationships between the individual actors and their interdependencies (Ghazawneh and Henfridsson, 2013; Selander et al., 2013), changing the direction and strength of ties among them (Basole, 2009).

\section{Conceptual framework: an actor network approach}

\subsection{Actor-network theory}

We argue that the interaction within the innovation ecosystem of a VPP, is strongly affected by human (i.e. organizational) and nonhuman (i.e. technological) actors. Thus, ANT is an appropriate starting point for the intercourse to our research design as it explicitly highlights this interplay (e.g. Callon, 1986; Latour, 1990, 2005). Despite being criticized, it is lately used to study innovation especially in the field of information systems (IS), which fits our perspective on the context of digital innovations (e.g. Dery et al., 2013; Hanseth and Lyytinen, 2004). In fact, several authors emphasized the importance of ANT in analyzing the interaction between stakeholders, particularly to address the crucial role of technology (e.g. Luoma-aho and Paloviita, 2010; Pouloudi et al., 2004; Vidgen and McMaster, 1996).

The origin of ANT, which lies within the field of socio-technological systems, implies that "[...] the study of any desired technology itself can be developed into a sociological tool of analysis [...]" (Callon 1987:83). Thus, the view of technology as a socially constructed system caused by several interactions perfectly fits our understanding (Hughes, 1987). Following this logic, the underlying concepts of ANT are inscription and translation (e.g. Callon, 1987; Lee et al., 2015). Engineers inscribe their intentions or imaginations of how it fits best to the desired scope into a developed or designed technical artefact (e.g. software, application). Callon (1987) titles such engineers as "engineer-sociologists" since they become sociologists in the way of inscribing their technical vision in the real world (organizational) context. In order to illustrate this, we give an evident example: Why do drivers trust their navigation systems at least as much as tourist information centers when searching a street? This is due to engineers inscribing navigation systems with specific respect to how drivers reach their way best as by those who once decided to develop a city guide (map). This plausible illustration highlights the central aspect of ANT of treating human and nonhuman actors equally. Throughout an innovation process, especially a 
digital innovation effort, it becomes increasingly difficult to recognize the frontiers between technical and social influence variables. In case of commonly acknowledged technology as social artefacts (see example above), the technology itself becomes an actor in terms of ANT. This actor then inherits the same characteristics as human ones (Callon, 1987; Latour, 2005). In fact, this feature of not distinguishing between human and non-human actors is "condition sine qua non" for Latour (2005), to test every study's valid claim of applying ANT.

\subsection{Conceptualizing digital ecosystems: an actor network perspective}

In this paper, we decided to apply ANT for several distinctive reasons. Firstly, ANT can be utilized as a framework for conceptualizing an innovation effort as an emerging network or ecosystem, which is exactly what we are aiming at. Despite having primarily, a social notation since persons are mainly responsible for the success or failure of innovation efforts, non-human actors like software, technology, grids etc. are also crucial in such projects (Callon, 1986; Hughes, 1987). In this context, non-humans (following Latour, 2005) are a series of heterogeneous inanimate actors called "agents" and must be extended to the understanding of "actors". Alternatively, the actor or agent is someone or something that produces an effect or change (Alter, 2013; Giddens, 1984). Examples for such "actants" are for instance technology, software, platforms as well as information content.

Secondly, only traditional actor roles as subject for investigation are considered, which is problematic since they exclusively act at the frontend of innovation (Jepsen and Eskerod, 2009). Hence, ANT allows an indepth understanding of the dynamics and the interaction among all actors influencing the outcome of an innovation and therefore the dynamics of an ecosystem. Ideally, ANT yields a basis for the examination on how actors form alliances, promote their ideas in front of other actors and use technology (artefacts) to work on their respective ties (Lee and Oh, 2006). In this context, Callon (1986) establishes the second principle of ANT, the translation. He defines it as the "methods by which an actor enrolls others" and is typically depicted via the four stages of problematization, interessments, enrolment and mobilization. As translation is not always successful, Callon (1986) further conducts that each entity could choose to either accept or refuse the translation, which is of course a significant aspect for the evolution of an innovations' ecosystem. Because it defines, which actors or entities are parts of the final ecosystem, which do have an active/supporting part, and which do not.

In sum, networks are no pre-existing entities solely consisting of pre-defined actors that collaborate in order to fulfil the project mission. Instead, they account for a volatile property emerging from relationships, which are the essence of the interaction between several actors (Callon and Law, 1995).

ANT (Callon, 1986; Callon and Law, 1995; Latour, 2005) is therefore most suitable to analyze relationship of heterogeneous actors in an ecosystem during value creation. Due to our research focusing on interorganizational innovation ecosystems, we define an organization as an entity of humans and thus a human actor.

As the architecture of digital innovation is typically following a layered modular logic (Yoo et al., 2010), the product can be decomposed into loosely coupled components interconnected through standardized interfaces (Schilling, 2000; Simon, 1962). These characteristics make the boundaries of the innovation fluid while the meaning is pre-specified. Following actor-network theorists such as Callon (1986) and Latour (1990), we assume that the digital innovation itself is a network of technological actors (components). Around this, a social network of human actors (i.e. organizations) emerges and coevolves with the technological network in reciprocal manner. Hence, human and non-human actors translate and inscribe their interests into a technology, creating an evolving network of human and technical entities (Aanestad and Jensen, 2011; Hanseth and Monteiro, 1997). We therefore define such an innovation ecosystem as a social technological system (actor network) consisting of two inseparable parts: a social system (human actor network) and a technological system (non-human actor network) (see Fig. 1).

In the sense of ANT, human actors inscribe their beliefs into a technological artifact. Vice versa, if a human actor uses a technological artifact, thus interacting with it, the affordances of the technological actor frame the initial beliefs of a human (Faraj et al., 2004). Therefore, the interactions between human and non-human actors can take several distinctive forms (see Table 1).

\subsection{Conceptualizing controversies as a source of ecosystem dynamics}

Ever since research started dealing with the management of innovation, different aspects were identified that have a crucial impact on the succession of the distinctive efforts. Hereby, a strong focus was naturally set on the framework in which an innovation is urged to act and thus influenced by several aspects that are not considered in the beginning. Such models view creative outcome like innovation as a process of random variation and selective retention (Campbell, 1960; Simonton, 1999). However, more recent research highlights the role of dialectics as a source and shaper of innovative outcome (Harvey, 2014). In this view on the evolution of creative artefacts conflicts and disagreement between actors provides opportunities for diverse viewpoints to be integrated in creative synthesis. In such settings dialectics arise through the social interaction between single actors that have divergent goals but converge their opinions in a creative synthesis (Kolb and Putnam, 1992)

Following this assumption of dialectics as a source and shaper of innovation, we relied on the concept of controversies from an ANT perspective to analyses opposing interests of several actors within a digital innovation ecosystem that contribute to the innovation and their effects on the very same (Latour, 2005; Venturini, 2010). Through an ANT lens', controversies are any aspects that contradict the status quo and thus influence the interaction and relationships between various actors within the innovation ecosystem (Latour, 2005). They span a broad range from the perception of the need for reciprocal consideration to the development of a compromise. Venturini (2010) defines controversies as dynamic conflicts that emerge when formerly fixed ideas and things are challenged and discussed. Extending the dialectic approach between social actors by applying ANT and the concept of controversies consequently provides a major benefit. ANT allows to include both human and technological actors as source of divergent viewpoints that can be integrated through synthesis and thus foster innovation and thus applies a socio-technological rather than a solely social perspective on the dialect perspective as driver of ecosystem evolution. We therefore propose that controversies are a suitable mechanism to explain the co-evolutionary interaction between human and non-human actors in an innovation ecosystem and thus reveal the dynamic of the actor network.

\section{Methodology}

\subsection{Research design}

As mentioned above, this paper presents the findings of an exploratory research based on an in-depth case study of a German utility setting up a VPP. The main objective of the project was to implement an innovative solution for the utility, which generates profits, and strengthen the image of the utility in the region alike. Hereby, our research questions have an exploratory character aiming at a deeper understanding of the underlying controversies of human and non-human actors within digital innovation ecosystems. For this reasons, we choose the case study approach that particularly allows to research into little explored topics with the purpose of theory building (e.g. Dul and Hak, 2007; Eisenhardt, 1989; Gillham, 2005). Contrary to other research strategies, the case study methodology is not intended to make 


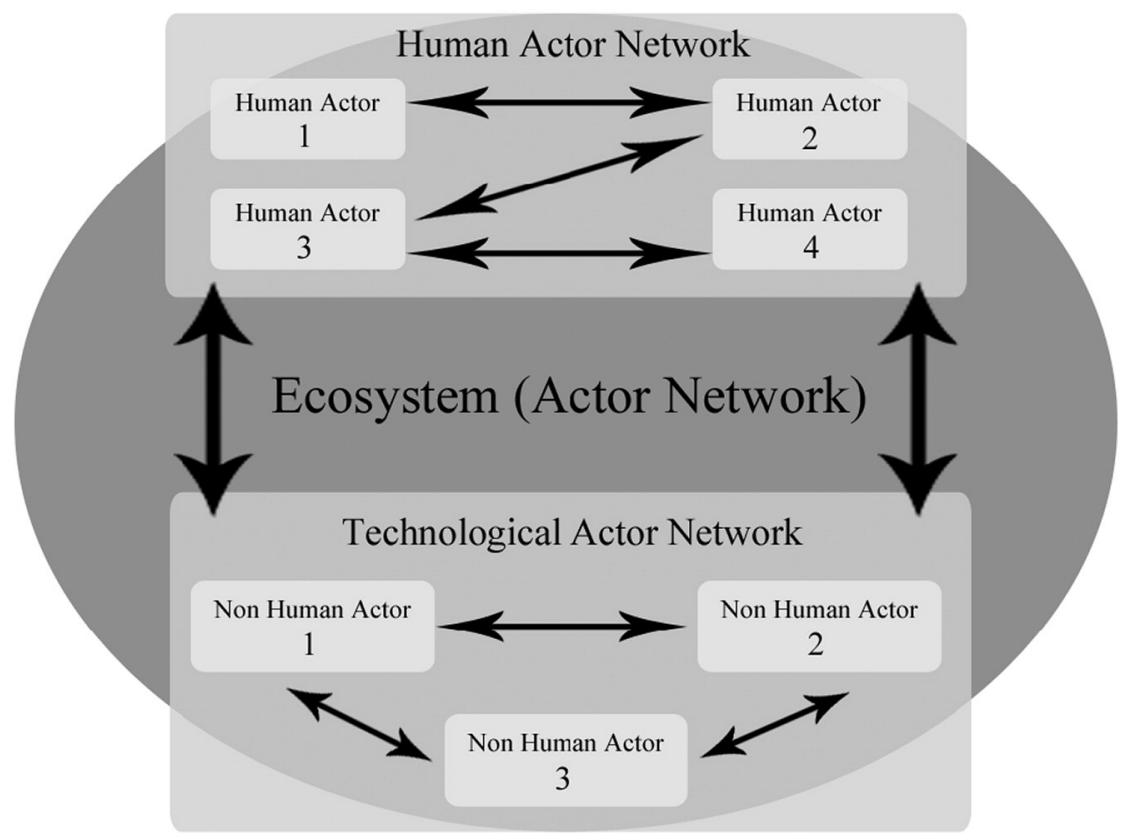

Fig. 1. Conceptualization of the innovation ecosystem as actor network consisting of human and non-human actors.

predictions about statistical relationships and frequencies (Eisenhardt and Graebner, 2007; Yin, 2013). Instead, the conclusions drawn from case study results are "[...] generalizable to theoretical propositions and not to populations or universes [...]" (Yin 2013: 13). In other words, we conducted this case study to gain new and useful insights on digital innovations in the energy industry and pointing to gaps in the existing theory on both the coevolution of digital innovation and ecosystems and beginning to fill them (Siggelkow, 2007). In line with this argumentation Lee et al. (2015) vote for applying ANT to new (digital) technologies in order to better understand the phenomena surrounding the technologies as well as to establish ANT as an empirical lens.

Thus, we choose the present case due to its exemplarity, which enabled us to apply our framework (Yin, 2013). In fact, a VPP provides us with a precious opportunity since the innovation on various actors across traditional industry boundaries and therefore highlights the importance of an innovation ecosystem (e.g. suppliers, complementors, national institutions, application interfaces etc.). In addition, the case offers the opportunity not just to identify but gain an in-depth understanding of controversies between the involved actors (human and non-human) alike.

The project kick-off started in May 2012 and finished in February 2015 as a whole. One of the authors had first-hand access since he participated in the project management team of the utility. Despite the involvement, the researcher aggregated the collected information and undertook participant observation in order to utilize the case study approach (Missonier and Loufrani-Fedida, 2014). To end up with unbiased results, the researchers were introduced to the project members as "neutral beholders" and did not intervene or act in any way. We found several controversies between human and non-human actors that have a crucial impact on the innovation and the ecosystem.

Table 1

Types of interaction.

\begin{tabular}{ll}
\hline Type of interaction & Practical example \\
\hline Human/human actor & Social interaction between two human entities \\
Non-human/non-human actor & Server-web browser interaction via TCP/IP \\
Human/non-human actor & Use of a technological artifact (software use) \\
\hline
\end{tabular}

\subsection{Data collection}

Regarding the collection of data, the triangulation of different methods is recommended in the literature to increase internal validity and to obtain a comprehensive description of the cases (Eisenhardt 1989; Yin, 2013). For an in-depth examination of the process and gaining valuable insights from mixed sources (Yin, 2013), we analyzed interviews, press articles and observations. In our study, data was primarily collected especially through semi-structured interviews with key actors (i.e. platform owner, suppliers, customers, marketers, grid operators) who were directly involved in the VPP project. We therefore ensure the acknowledgement of various perspectives. First, we conducted 20 semi-structured interviews to gain access to rich empirical data (Eisenhardt and Graebner, 2007). Second, we collected, clustered and listed 36 press articles and official documents along with internal and private documents (partnership agreements, supplier conditions, legal documents etc.). Third, the experience of observations in 121 days of participation in the project was beneficial.

\subsection{Data analysis}

We transcribed all interview and asked the interviewees to review our case write-ups to verify our analysis. In the next step, we followed the analysis principles of Glaser and Strauss (1967). First, we used open coding to identify single controversies, involved actors, their corresponding links and key events. After that, we applied we relied on principles of Latour (2005) and recommendations by Venturini (2010) to identify and analyze controversies within the innovation ecosystem. Furthermore, we used the underlying logic of the markers of Missonier and Loufrani-Fedida (2014), which were developed for the special case of innovation in information systems. Slightly differing but nonetheless comparable our markers include the following five dimensions namely (1) the subject of the controversy, (2) the involved actors (along with their respective interests), (3) the synthesis that solves the controversy, (4) the effect on the actor network and (5) consequential controversies. Hereby, our major goals were not only to identify the controversies but also to examine the type of controversy, the mechanism and the pathway of evolution of the innovation ecosystem. 


\subsection{The VPP setting}

The challenge to plan and implement the German energy transition (GET) causes fundamental changes in the energy industry. However, another even more significant upheaval, which affects the sector, is the emergence of digitalization. Hereby, digitalization offers chances not only to revolutionize the market but also to exacerbate the transformation of the logic of energy business in general.

Industry dynamics explain how actors in a distinctive industry interact through either collaboration or competition with each other. Hereby, the German energy industry is no exception. For German energy suppliers, times of singular electricity selling as solid sources of income are over. Traditionally, the success of companies in this industry was defined by the ownership of big power plants, which become increasingly obsolete. Realizing this trend and including it in one's own innovation strategy is crucial for firms competing in energy markets. Especially, municipal utility companies that rely heavily on conventional (fossil) power plants are facing significant disruption through the increasing capacity additions of renewable energies (RE). One major issue, which is often not considered, is the strong need of RE's for a strong infrastructure, which enables reliable power transmission in times of no wind and sun. Mainly because of the highly fluctuating feed-in times of RE, a stable energy supply and in special a reliable base load has become a greater challenge than in previous years. Additionally, the formerly rigid German energy industry is characterized by an increasing decentralization as thousands of small and local units instead of big centralized plants pre-dominantly generate energy. In line with this development, an increasing number of novel actors entered the market and even the role models for traditional players in the industry shifted. For example, private households with a PV-panel on the roof and storage units evolve from single consumers to prosumers (producers and consumers alike). As a follow, tens of thousands of such small power producers have to be managed and their electricity flows must be gathered and orchestrated to feed it into the grid and to the market. Virtual power plants (VPP) aim at providing a solution; since they connect several decentralized power generating units (foremost RE such as photovoltaic, wind farms and biogas plants). In general, VPPs must be regarded as an emerging technological trend in the energy industry. A virtual power plant can be defined as a cluster of grid connected micro-power units that is monitored and controlled on an aggregate level by a VPP operator for commercial or technical objectives. A VPP is used to participate in trade on energy markets (APX, EEX), which is enables by the technological distribution network management such as providing regulating and reserve power. As stated above a VPP (or VPPs in general) are technological innovation that combines various stakeholders (actors) in an innovation ecosystem. Therefore, the case study uses one technological instantiation of a VPP as setting, while VPPs in general refer to one type of steering distributed power systems.

Due to the virtual connection (via tele control boxes and API's) and creation of a generation mix they can balance and compensate the different decentral knots (see Fig. 2).

Since this novel and decentralized way of generating, steering and commercialize energy requires digital connection between all actors via IT, this innovation effort can be marked as a digital innovation. Further, the very central concept of this business model is relying on collaboration or connectedness whereas the ecosystem mainly defines this dependence on each other. In conclusion, our case is appropriate since it combines the feature of digitization (technology-dependence) as well as a highly dependence on the innovation ecosystem and thus is a perfect setting for our analysis.

\section{Findings}

The apprehended case can be sub-divided into two controversy loops, which must be regarded as consecutive with respect to the total ecosystem dynamics.

The first loop, which is illustrated in-depth in Fig. 3, arose from a mundane problem. The platform owner who was eager to coordinate the single actors of the ecosystem timely faced several complaints of customers. Caused by crucial delays of the initial tele-control boxes supplier the customers were not connected to the pool in the promised period of time, which led naturally to dissatisfaction and sunken revenues. The problem was caused by understaffed work force of the supplier and delays in the development of the network compatibility. Thus, the platform owner was forced to drain the responsibility of the installation process from hardware supplier in order to ensure a successful business case. Fortunately, an agreement with a new service provider could be reached who took over the whole hardware delivery and installation part.

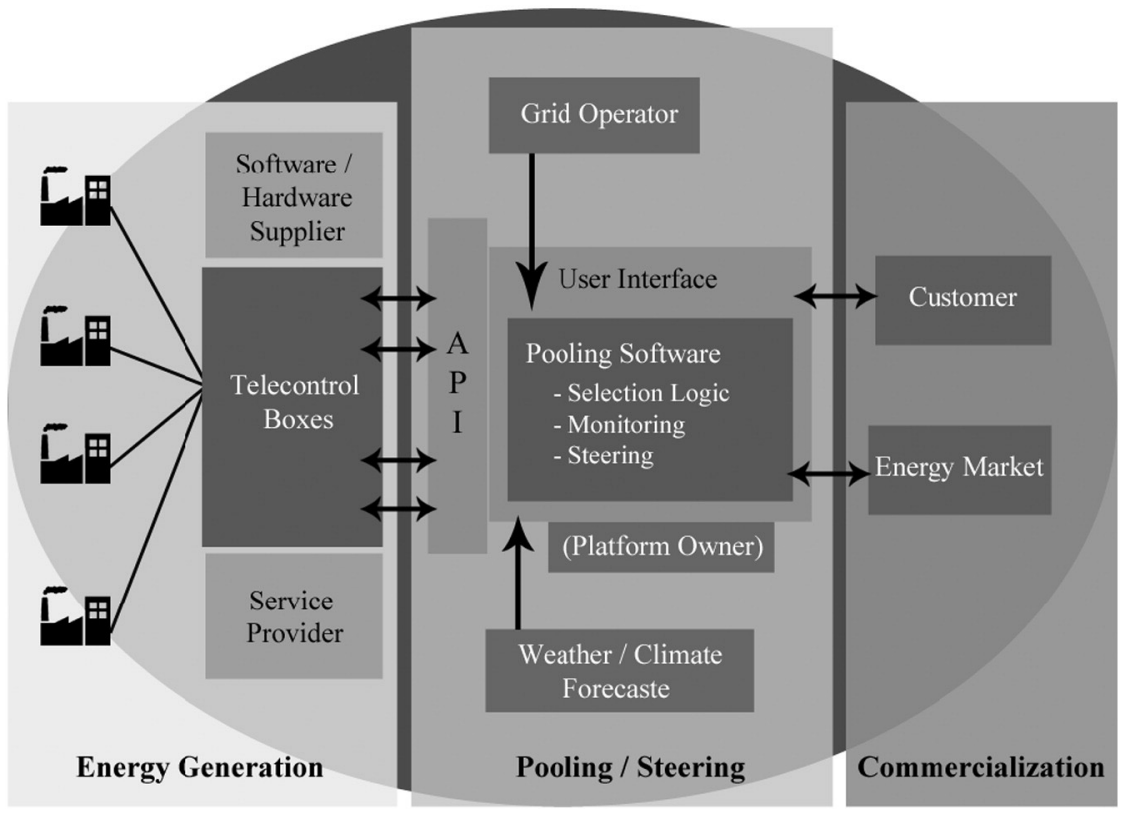

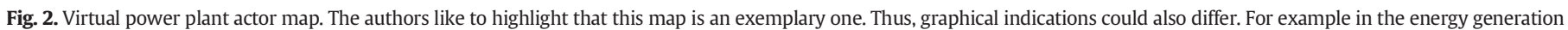
frame all kinds of possible renewable energy plants can be synonymously substituted such as in form of wind or solar units. 


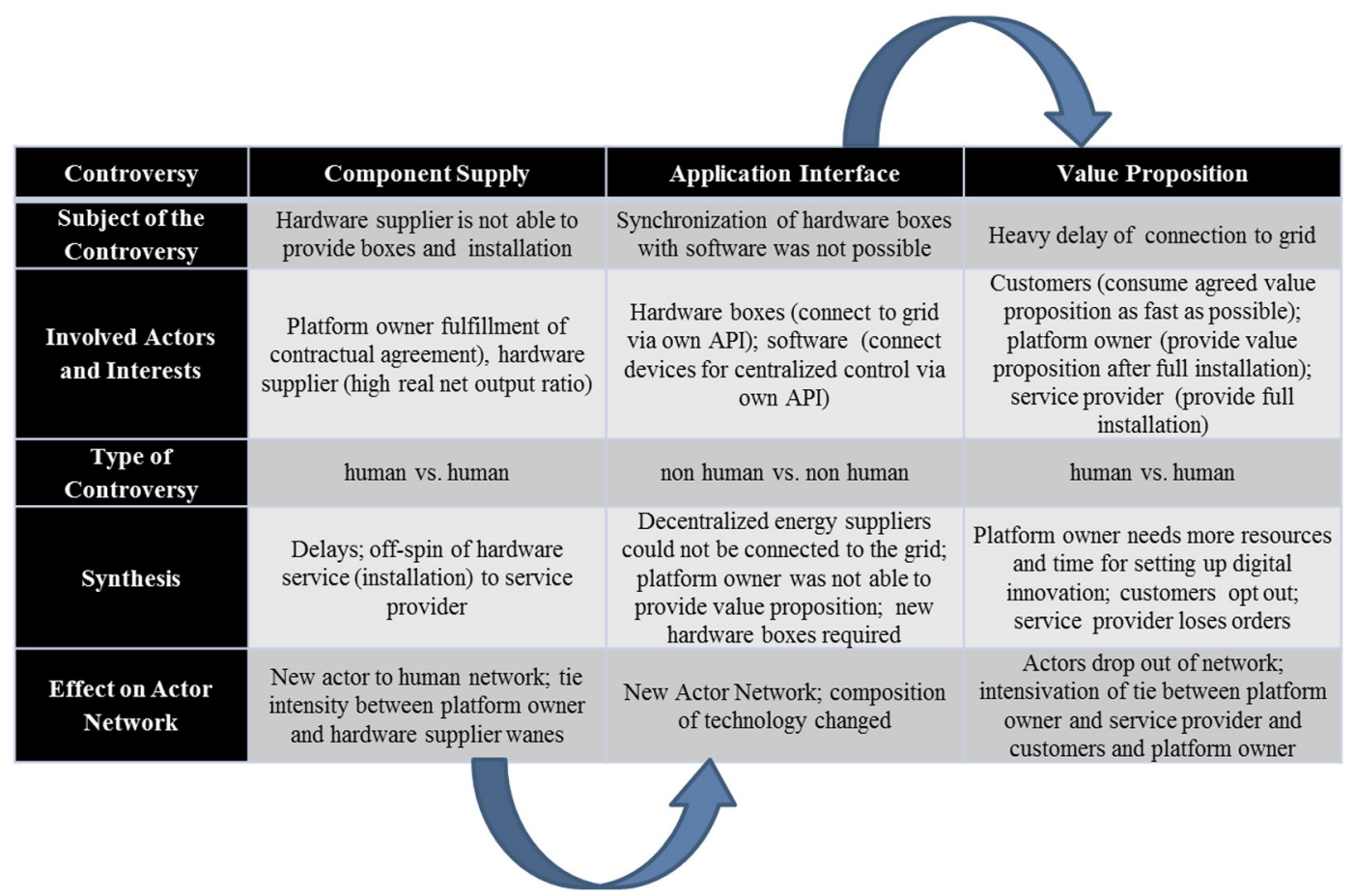

Fig. 3. First controversy loop.

Another problem arose when the new hardware boxes were not suitable for synchronization with the software of the platform. While the hardware boxes tend to connect to the grid via an own application interface (API) the software was designed to connect all devices for a centralized control via its own API. This was a system-threatening issue since the focal value proposition of the virtual power plant was under attack. The platform owner was forced to substitute the hardware supplier, which had an impact on the actor network in form of an adjusted component (supplier). While all this actions and coordination took its time, heavy delays of the project were inevitable. The launch date to the grid, which equally marks the start of value generation, postponed several times. A remarkable amount of plant operators opt-out during this process and the remaining actors were forced to strengthen their relationships in order to avoid the failure of the project. During this process, the platform owner had many controversial discussions with plant operators and customers trying to smooth the moods.

Besides these technical controversies, a second loops could be recognized which had more of a conceptual nature (see Fig. 4).

First, the commercial exploitation and the way to market it was a basis of a conflict. The platform owner who is himself embedded in an organizational network pledged for a collaborative approach for the marketing efforts. In contrast, the initial marketer, who is simultaneously the central service unit of the network the platform owner is embedded, was eager to develop a stand-alone solution. After several unfruitful debates over the pros and cons of each approach both opinions were incompatible. Thus, the ecosystem changed again, since the

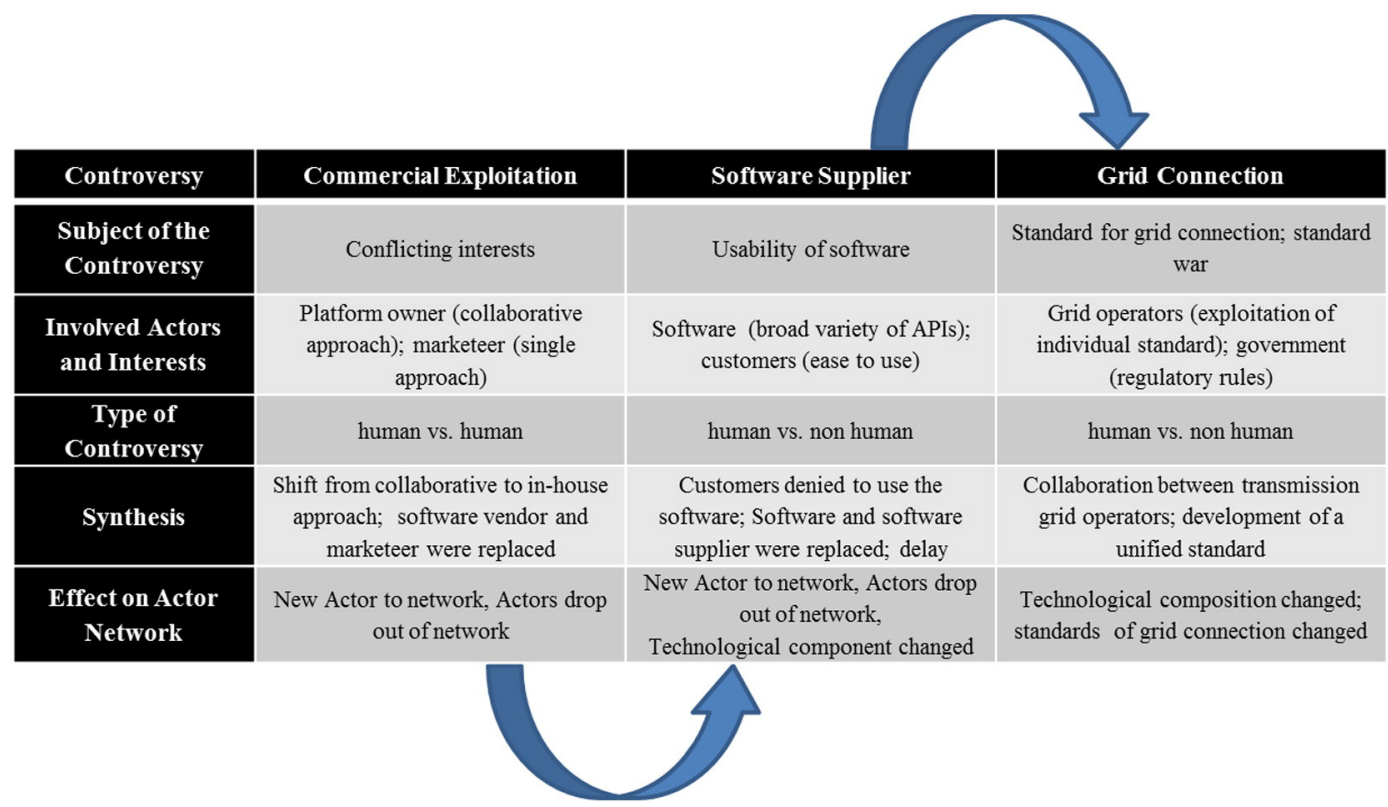

Fig. 4. Second controversy loop. 
software vendor (who was connected to the marketer) as well as the marketer were replaced by the platform owner. Second, the substitution of the software vendor led to a broad variety of APIs in the system and thus belittle the ease of use for the customers. Customers denied the use of the offered software and the market software itself as well as supplier were again replaced. Third, the connection to the grid was affected by this replacement too. While the grid operator was willing to exploit the heterogeneity of the individual standards (Germany can be divided in four grid zones), the government planned to establish a regulatory standard for the whole of Germany. Thus, all of the four transmission grid operators collaborated to set a German-wide standard protocol for platform operators. Since this was a different standard from the one of the case company, all installed boxes at the plant operators must be reworked while the costs were not refunded.

Our findings reveal that throughout the whole process of establishing a VPP several controversies occur and influence the coevolution of the innovation ecosystem as well as the innovation. As the respondents highlight, controversies do not only shape the configuration of the innovation ecosystems evolution; they additionally define the whole composition of the structure as well as the target corridor responsible for the selection of each individual actor. These influenced the ecosystem in a way that resulting controversies consecutively required an atmosphere of re-adjustments and re-configuration.

During the interviews, it became obvious that two distinctive controversy tracks were pre-dominant within our case. The first one evolved mainly on a technical level since it deals with the appropriateness of components and the selection of suitable suppliers. In contrast, controversies shaped the second track mainly regarding the personal and technical requirements of actors and their respective distribution within the ecosystem as a whole including responsibilities and task definitions.

With respect to the first track, the focal controversy arose between two organizational entities (human actors), the hardware supplier and the platform owner covering the in-ability of the hardware supplier to provide the assured control boxes and installation in the agreed quantity and time. Hereby, a re-adjustment of the constellation of the innovation ecosystem was necessary and the platform owner re-allocated the responsibility for the installation from the supplier towards a service provider. As the Head of the Project stated "[...] for us, it was absolutely inacceptable to stave off the customers, since we vouched with our reputation to ensure the installation in-time. Due to the delays we were forced to evaluate other alternatives and while we mandated the service provider the relationship with the hardware supplier was strained [...]". In the follow, a new actor who was previously not considered entered the ecosystem and the hardware supplier was complemented. For this reason, a change in the technological components of the VPP compared to the initial innovation setting was implemented and required an adjustment by the other established actors. This evolution of the ecosystem and the resulting reconfiguration of the VPP's components resulted in a consecutive controversy.

The application interface between two non-human actors, the hardware boxes and software platform was not compatible anymore. Hence, the connection of the decentralized power suppliers to the grid was no longer possible. Consequentially, the platform owner could not provide the proposed value proposition to the customer. The opposing interests between the single components of the VPP, the hardware boxes and the software layer, led to a controversy that affected the need for a reconfiguration of the components of the VPP to ensure the functionality of the innovation. Consequently, the reconfiguration of the constellation of the innovation ecosystem and hence the entrance of a new provider for hardware boxes was required. Since the platform owner was forced to re-design the network, this internal process was delaying the installation deadline promised to the customers. The customers were not contented by the ongoing delays and began to discuss the contractual agreements with the platform owner. This controversy exclusively between human actors (the platform owner and the customers) led to a re-adjustment of the planned costs for the platform owner, losses of already signed customers and losses of orders for the service provider. In contrast, the remaining actors intensified their collaboration, which ensured a better and more amicable understanding. A Sales Manager highlighted, that "[...] it was quite difficult to keep the customers in line since they were understandably not happy with the delays. They were afraid of financial losses and actively searching for new alternatives and marketers. Thus, handling the inner controversies had a high priority in order to avoid market losses [...]". A Project Manager also added "[...] we were forced to solve this controversy as soon as possible since it connotes for significant financial losses on our side. Unfortunately, there was no majority opinion on who was responsible for the installation (service provider alone or in collaboration) in order to fulfill the designated dates. Each party was eager to receive the responsibility for providing this service after the designated actor (hardware box supplier) dropped out since it involves earning additionally revenues [...]". This controversy resulted in an evolution of solely the innovation ecosystem as some customers (human actors) dropped out.

The second track of controversies was more on a generalized level influencing the configuration of the ecosystem. As often in business cases, when several heterogeneous partners are forced to co-ordinate their actions which each other, controversies arose. First to mention are the conflicting interests on a human actor's level. For example, between the platform owner and the platform operator, the conflict inherits the question of how deeply the marketing and accounting activities are consolidated.

"[...] It comes as no surprise that every enterprise whether operating in a collaboration or in a single-handed business venture tries to maximize their profits. Unfortunately, the value chain is most often limited and predefined so that an allocation of the profits and revenues is inevitable. For this reason, most of the struggles or controversies as you would put it, arose in the forefront of a innovation project. Each party tries to scavenge the biggest piece of pie and naturally the distribution of tasks which is related to this allocation is heavily embattled [...]" as the Senior Product Manager stated.

As no compromise, could have been reached, the platform owner replaced both the platform operator and the marketers leading to a change in the constellation of the ecosystem while the innovation remains untouched. In a follow, the new software supplier had difficulties to ensure the compatibility of his software solution to a broad variety of API's while the customers favored the usability of the software interface. The consequence was that this human vs. non-human controversy led to a rejection of the customers to use the solution. The software supplier was substituted and a more customer-friendly but less complex and applicable software solution was implemented. A new actor and results in the reconfiguration of the technological components of the VPP enlarged the evolution of the innovation ecosystem. The last issue for itself was a sum of controversial interests for the grid operators whose aim was to synchronize all transmission codes across the German energy market and standardize the connection for all feed-in of VPPs. As the responsible manager of the grid operator puts it "[...] the main difficulty was the co-ordination between all actors. The four transmission grid operators aimed at standardizing the feed-in options for all power plant operators. On the other side, most VPP's are handled very heterogeneous in terms of software codes, connection points and commercial exploitation. We are obliged to offer every system the feed-in but since there are so many different solutions it can took time. A retrofitting to a standardized system, which would on the other hand accelerate the process, is most often too expensive for the system operators [...]". The foremost agreements were in consequence not valid anymore and the grid operator was forced to re-code the connection ports, which exacerbates the delay discussion with the customers for the platform owner. Hence, the changes of the transmission standards of the VPP required an adaption of the technological components and lead to an evolution of the digital innovation, namely the VPP. 


\section{Discussion}

The gained insights enabled us to regard controversies not only as concomitant in setting up the VPP but also rather as a constitutional factor determining the coevolution of the innovation ecosystem as well as the configuration of the digital innovation itself.

\subsection{A typology of controversies in innovation ecosystems}

The layered modular architecture of digital innovation including single components that interact and are provided by heterogeneous firms, lead to the fact that not only human actors (organizations) but also technological actors can create controversies due to antithetical interests. This effect is particularly important for the layered modular architecture of digital innovation (Yoo et al., 2010). With respect to our first research question, our findings reveal three types of controversies (Fig. 5).

First, controversies can arise due to disagreement of organizations (human/human) about certain topics like contractual agreements, target dimensions, participation and resource allocation (Type I). Such controversies are for instance interpersonal conflicts. Therefore, ANT explains the process in which actors form alliances and promote their point of views to convince other actors in the ecosystem.

Second, following this logic, even non-human/non-human conflicts are possible as digital technology is combining digital and physical components and enables the interconnection of loosely coupled components through standardized interfaces (Type II). The non-interoperability of technological components is a shared uncertainty between actors as the requirement specification may exceed the range of functions. Therefore, for instance technological protocols for communication might not be interoperable and create controversies between technological artifacts.

Third, especially in digital innovation, non-human actors (technology) can trigger controversies (Type III). As, for instance, the engineers encoded their respective visions about application into a software code, the software itself utilized by the platform owner becomes an individual actor within the innovation ecosystem with own interests and requirements. Therefore, human/non-human controversies can arise as for instance the usability of technology might then lead to opposing interest with the user. Therefore, uses might resist using a software artifact leading to controversies between human and non-human actors.

In addition, a match between our paper and the study for standardization and ANT can be stated (Lee and Oh, 2006; Lee et al., 2015). In line with this argumentation and our findings, standard wars must be considered as a framework heavily affected by technological actors. Standardization which is a significant factor for digitization since it aims at contributing world-wide services and applications in the same "language" is often area for alliances favoring a specific technology which is to become global standard.

\subsection{The mechanisms of how controversies drive the coevolution within in- novation ecosystem}

The coevolution within the innovation ecosystem is determined by dynamic interactions between actors that try to achieve a common goal. As the characteristics of the ecosystem itself (e.g. coopetition) and the process of establishing common goals is marked by the pondering of which way is the most appropriate to achieve them they are often shaped by disagreement, negotiation and alliance formation. Hence, these mechanisms, commonly known as controversies, are a suitable way to describe the dynamics of the ecosystem, as the digital innovation is not a static construct. Our findings reveal that controversies not only shape the coevolution but also even originate it. Following this argumentation, controversies are not only a negative aspect but also the various interests of human and non-human actors actively shape and improve the composition of the ecosystem as well as the innovation as they foster the way of reflective consideration toward the most suitable outcome. The findings within our case reveal that controversies can have different effects on the social system (human actor network) as well as the technological system (non-human actor network) (Fig. 6).

In the context of interdependent actors within an ecosystem, the outreach of a controversy goes beyond dyadic relations. Hence, a controversy can also have indirect effects on actors within the ecosystem and create consequential conflicts. The reconfiguration of an ecosystem can create a helix of consequential conflicts that lead to further evolution of the ecosystem as well as the innovation. Due to the multiplexity of relations and interdependencies within ecosystems, the change of constellations of actors may affect the whole ecosystem as the

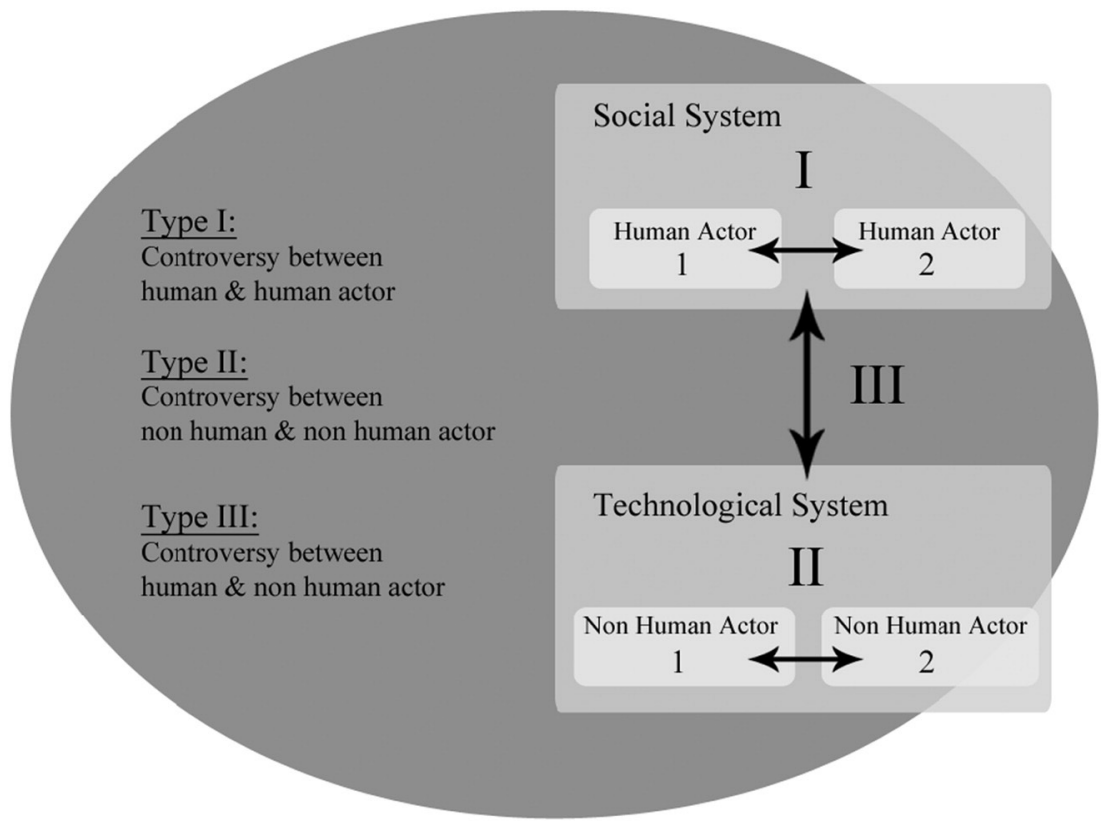

Fig. 5. Typology of controversies in innovation ecosystems. 

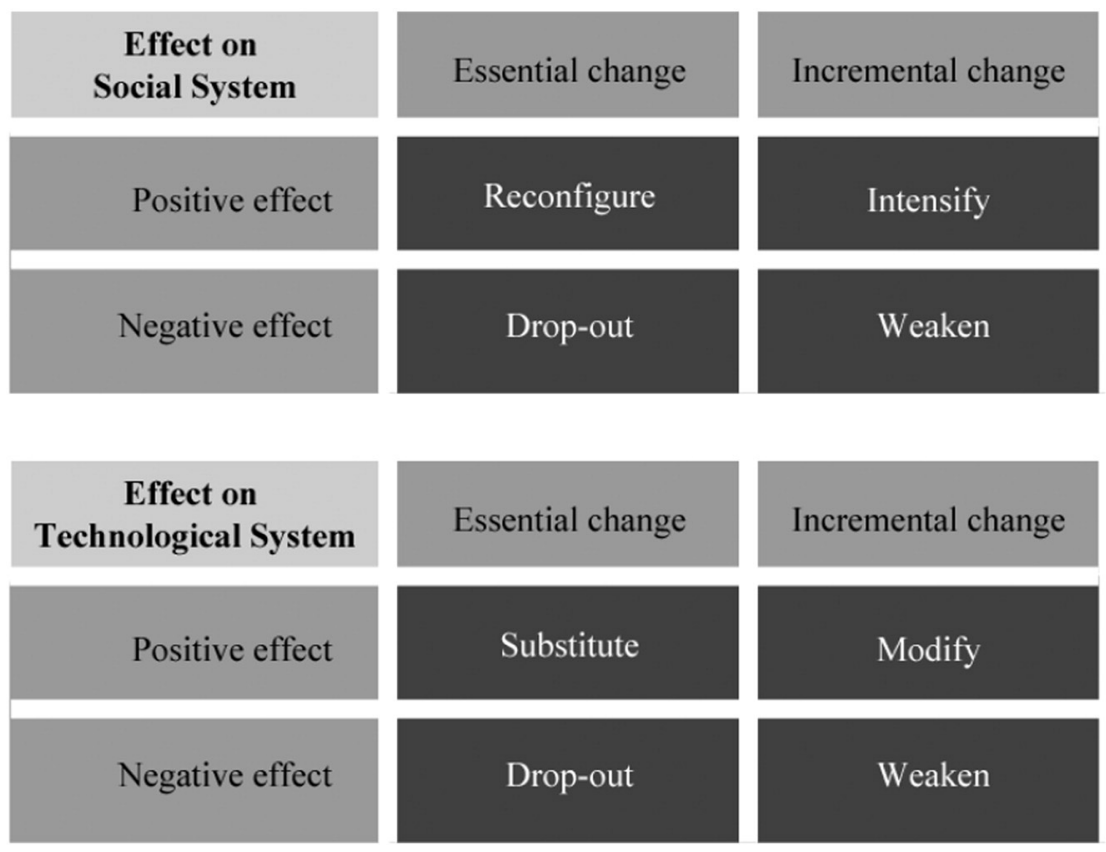

Fig. 6. Mechanisms of controversies in innovation ecosystems.

reconfiguration of interests and reallocation of resources can lead to new controversies.

\subsection{The logic of ecosystem dynamics}

Based on our case study findings we have examined that the coevolution of human and non-human actor networks, which is induced by controversies within an innovation ecosystems follows three pathways (Fig. 7).

First, the logic of coevolution resulting from a controversy can have an upstream ripple effect. This means controversies that result in the reconfiguration of the technological actor network can affect the constellation of the human actor network and therefore lead to ecosystem dynamics (path 1).

Second, the controversy can shape the ecosystem by adding new actors, removing actual ones or exchanging human and non-human actors. The reconfiguration of the network of human actors (i.e. organizations) can further directly affect constellation of technological components. Adding new actors that inscribe their respective interests into the technological components is frequently changing the architecture of the digital innovation. Thus, a downstream ripple effect can create the coevolution logic of the ecosystem. For instance, the reconfiguration of human actors resulting from a controversy might induce a consecutive controversy among non-human actors (path 2).

Finally, the third logic of co-evolution must be regarded twofold. On the one side, a controversy may result in a change of the constellation of the human actor network without change of the technological network. This is mostly the case when similar actors substitute actors, which do not require changes in the technological network (path 3a). On the other hand, controversies can induce a redefinition of the technological network without changes in the respective human network. Hereby, the flexibility of the current organizations within the ecosystem is challenged. This is the case if they can fulfil adjustments required from technological changes without any profound evolution of the organizational constellation (path 3b).

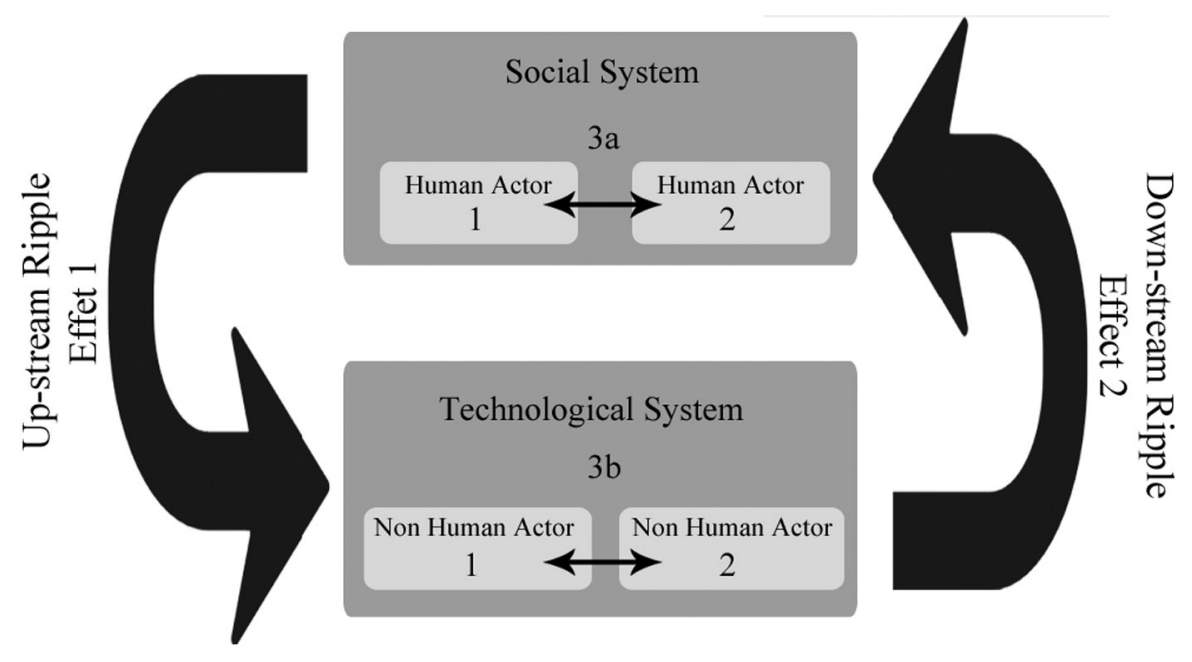

Fig. 7. Path logic of ecosystem evolution. 


\section{Conclusion}

Our primary objective in this paper is to analyze the dynamics of innovation ecosystems. In particular, we attempt to shed light on how controversies between human (organizational) and non-human (technological) actors coevolve and shape the evolution process of an innovation ecosystem.

The results of our qualitative case study of a VPP project in the German energy industry provide several interesting insights for both theory and practice.

By applying ANT, this paper contributes to research on ecosystem dynamics (Ravasz and Barabási, 2003; Um et al., 2013) and innovation evolution (Audretsch, 1995; Nelson and Winter, 2009). In particular, we extend previous research on dialectics and creative synthesis in groups as source of innovative outcomes (e.g., Harvey, 2014) by applying an interorganizational level of analysis. Moreover, we extend this research by highlighting the role of technological actors in the dialectic process of ecosystem evolution. Our results provide an integrated view of the interaction between both, technological and social entities and how these affect dynamics of an innovation ecosystem. We therefore show different typologies of controversies, their mechanisms as well as their pathway of influencing ecosystems. Our work reveals that social and technological networks within an innovation ecosystem are reshaped by controversies between human and non-human actors, which underline the postulate of Orlikowski and Iacono (2001) for theorizing the role of (information) technology.

Based on our key findings implications for managers as well as practitioners can be derived. Firstly, it is worth acknowledging that technology is not only a tool but has a far more significant role. While several key inscriptions via the designers lead to a more active role, technology itself must be valued more in-depth since it is often fundamental for the collaboration of the majority of actors und thus becomes a non-human actor itself. We discovered that these non-human (technological) actors play a crucial role as they can also create controversies due to their inscripted interests. Secondly, managers must be aware that the substitution of one actor within the innovation ecosystem not necessarily leads to a frictionless procedure. Even if the substitute can cover the workload on an operational basis, the adjustments and ties towards other actors must be established to prevent further conflicts. Vice versa, changes of the technological components of the innovation can influence the ecosystem. Therefore, we suggest that managers should pay critical consideration on the role of technology.

However, this work is not without limitations. Although the boundaries of the innovation were not predetermined a priori in the case of VPPs, this innovation has the pre-specified goal of orchestrating decentral energy suppliers. The question arises what role the mechanisms of controversies play in digital ecosystems that are created for generativity (e.g. software-based platforms). Further research could examine the applicability of this mechanism for other types of innovation apart from digital technology.

\section{References}

Aanestad, M., Jensen, T.B., 2011. Building nation-wide information infrastructures in healthcare through modular implementation strategies. J. Strateg. Inf. Syst. 20 (2), $161-176$.

Adner, R., 2006. Match your innovation strategy to your innovation ecosystem. Harv. Bus. Rev. 84 (4), 98-107.

Adner, R., Kapoor, R., 2010. Value creation in innovation ecosystems: how the structure of technological interdependence affects firm performance in new technology generations. Strateg. Manag. J. 31 (3), 306-333.

Adomavicius, G., Bockstedt, J.C., Gupta, A., Kauffman, R.J., 2008. Making sense of technology trends in the information technology landscape: a design science approach. MIS Q. 779-809.

Alter, S., 2013. Work system theory: overview of core concepts, extensions, and challenges for the future. J. Assoc. Inf. Syst. 14 (2), 72-121.

Atzori, L., Iera, A., Morabito, G., 2010. The internet of things: a survey. Comput. Netw. 54 (15), 2787-2805.

Audretsch, D.B., 1995. Innovation and Industry Evolution. Mit Press.

Baldwin, C.Y., Clark, K.B., 2000. Design Rules: The Power of Modularity.
Basole, R.C., 2009. Visualization of interfirm relations in a converging mobile ecosystem. J. Inf. Technol. 24 (2), 144-159.

Battistella, C., Colucci, K., Toni, De, Alberto, F., Nonino, F., 2013. Methodology of business ecosystems network analysis: a case study in telecom Italia future centre. Technol. Forecast. Soc. Chang 80 (6), 1194-1210.

Callon, M., 1986. Some Elements of a Sociology of Translation: Domestication of the Scallops and the Fishermen of St. Brieuc Bay. Power, Action, and Belief: A new Sociology of Knowledge 32, pp. 196-223.

Callon, M., 1987. Society in the making: the study of technology as a tool for sociological analysis. The Social Construction of Technological Systems: New Directions in the Sociology and History of Technology, pp. 83-103.

Callon, M., Law, J., 1995. Agency and the hybrid «collectif». S. Atl. Q. 94 (2), 481-507.

Campbell, D.T., 1960. Blind variation and selective retentions in creative thought as in other knowledge processes. Psychol. Rev. 67 (6), 380.

Chesbrough, H.W., 2006. Open Innovation: The new Imperative for Creating and Profiting From Technology. Harvard Business Press.

Dery, K., Hall, R., Wailes, N., Wiblen, S., 2013. Lost in translation? An actor-network approach to HRIS implementation. J. Strateg. Inf. Syst. 22 (3), 225-237.

Dul, J., Hak, T., 2007. Case Study Methodology in Business Research. Routledge.

Eisenhardt, K.M., 1989. Building theories from case study research. Acad. Manag. Rev. 14 (4), 532-550.

Eisenhardt, K.M., Graebner, M.E., 2007. Theory building from cases: opportunities and challenges. Acad. Manag. J. 50 (1), 25-32.

Faraj, S., Kwon, D., Watts, S., 2004. Contested artifact: technology sense making, actor networks, and the shaping of the web browser. Inform. Technol. People 17 (2), 186-209.

Garud, R., Kumaraswamy, A., 1993. Changing competitive dynamics in network industries: an exploration of Sun Microsystems' open systems strategy. Strateg. Manag. J 14 (5), 351-369.

Ghazawneh, A., Henfridsson, O., 2013. Balancing platform control and external contribution in third-party development: the boundary resources model. Inf. Syst. J. 23 (2) $173-192$.

Giddens, A., 1984. The Constitution of Society: Outline of the Theory of Structuration. Univ of California Press.

Gillham, B., 2005. Research Interviewing: The Range of Techniques: A Practical Guide McGraw-Hill Education (UK).

Glaser, B.G., Strauss, A., 1967. The discovery of ground theory. Alpine, New York.

Hanseth, O., Lyytinen, K., 2004. Theorizing About the Design of Information Infrastructures: Design Kernel Theories and Principles. Sprouts: Working Papers on Information Environments, Systems and Organizations vol. 4 No. 4 pp. 207-241.

Hanseth, O., Monteiro, E., 1997. Inscribing behaviour in information infrastructure standards. Account. Manag. Inf. Technol. 7 (4), 183-211.

Harvey, S., 2014. Creative synthesis: exploring the process of extraordinary group creativity. Acad. Manag. Rev. 39 (3), 324-343.

Henfridsson, O., Bygstad, B., 2013. The generative mechanisms of digital infrastructure evolution. MIS Q. 37 (3), 907-931.

Hughes, T.P. 1987. The evolution of large technological systems. The Social Construction of Technological Systems: New Directions in The Sociology and History of Technology, pp. 51-82.

Iansiti, M., Levien, R., 2004. Strategy as ecology. Harv. Bus. Rev. 82 (3), 68-81.

Jepsen, A.L., Eskerod, P., 2009. Stakeholder analysis in projects: challenges in using current guidelines in the real world. Int. J. Proj. Manag. 27 (4), 335-343.

Kolb, D.M., Putnam, L.L., 1992. The multiple faces of conflict in organizations. J. Organ. Behav. 13 (3), 311-324.

Latour, B., 1990. Technology is society made durable. Sociol. Rev. 38 (S1), 103-131.

Latour, B., 2005. Reassembling the social-an introduction to actor-network-theory. Reassembling the Social-An Introduction to Actor-Network-Theory, by Bruno Latour Foreword by Bruno Latour vol. 1. Oxford University Press, p. 316 (Sep 2005. ISBN-10: 0199256047. ISBN-13: 9780199256044)

Lee, H., Oh, S., 2006. A standards war waged by a developing country: understanding international standard setting from the actor-network perspective. J. Strateg. Inf. Syst. 15 (3), 177-195.

Lee, H., Harindranath, G., Oh, S., Kim, D.-J., 2015. Provision of mobile banking services from an actor-network perspective: implications for convergence and standardization. Technol. Forecast. Soc. Chang. 90, 551-561.

Luoma-aho, V., Paloviita, A., 2010. Actor-networking stakeholder theory for today's corporate communications. Corp. Commun. Int. J. 15 (1), 49-67.

Missonier, S., Loufrani-Fedida, S., 2014. Stakeholder analysis and engagement in projects: from stakeholder relational perspective to stakeholder relational ontology. Int. J. Proj. Manag. 32 (7), 1108-1122.

Moore, J.F., 1993. Predators and prey: a new ecology of competition. Harv. Bus. Rev. 71 (3), 75-83.

Nambisan, S., Baron, R.A., 2013. Entrepreneurship in innovation ecosystems: entrepreneurs' self-regulatory processes and their implications for new venture success Enterp. Theory Pract. 37 (5), 1071-1097.

Nelson, R.R., Winter, S.G., 2009. An Evolutionary Theory of Economic Change. Harvard University Press.

Orlikowski, W.J., Iacono, C.S., 2001. Research commentary: desperately seeking the "IT" in IT research-a call to theorizing the IT artifact. Inf. Syst. Res. 12 (2), 121-134.

Pouloudi, A., Gandecha, R., Atkinson, C., Papazafeiropoulou, A., 2004. How stakeholder analysis can be mobilized with actor-network theory to identify actors. Information Systems Research. Springer, pp. 705-711.

Ravasz, E., Barabási, A.-L., 2003. Hierarchical organization in complex networks. Phys. Rev E 67 (2), 026112.

Schilling, M.A., 2000. Toward a general modular systems theory and its application to interfirm product modularity. Acad. Manag. Rev. 25 (2), 312-334. 
Schumpeter, J., 1942. Creative Destruction.

Selander, L., Henfridsson, O., Svahn, F., 2013. Capability search and redeem across digital ecosystems. J. Inf. Technol. 28 (3), 183-197.

Siggelkow, N., 2007. Persuasion with case studies. Acad. Manag. J. 50 (1), 20-24.

Simard, C., West, J., 2006. Knowledge networks and the geographic locus of innovation. Open Innovation: Researching a New Paradigm, pp. 220-240.

Simon, H.A., 1962. The architecture of complexity. Proc. Am. Philos. Soc. 106 (6), 467-482.

Simonton, D.K., 1999. Creativity as blind variation and selective retention: is the creative process Darwinian? Psychol. Inq. 309-328.

Sosa, M.E., Eppinger, S.D., Rowles, C.M., 2004. The misalignment of product architecture and organizational structure in complex product development. Manag. Sci. 50 (12), 1674-1689.

Staudenmayer, N., Tripsas, M., Tucci, C.L., 2005. Interfirm modularity and its implications for product development*. J. Prod. Innov. Manag. 22 (4), 303-321.

Teece, D.J., 2007. Explicating dynamic capabilities: the nature and microfoundations of (sustainable) enterprise performance. Strateg. Manag. J. 28 (13), 1319-1350.

Um, S., Yoo, Y., Wattal, S., Kulathinal, R., Zhang, B., 2013. The Architecture of Generativity in a Digital Ecosystem: A Network Biology Perspective.

Venturini, T., 2010. Diving in magma: how to explore controversies with actor-network theory. Public Underst. Sci. 19 (3), 258-273.
Vidgen, R., McMaster, T., 1996. Black boxes, non-human stakeholders and the translation of IT through mediation. Information Technology and Changes in Organizational Work, pp. 250-271.

Yin, R.K., 2013. Case Study Research: Design and Methods. Sage Publications.

Yoo, Y., Henfridsson, O., Lyytinen, K., 2010. Research commentary-the new organizing logic of digital innovation: an agenda for information systems research. Inf. Syst. Res. 21 (4), 724-735.

Michael Kolloch is Research Fellow and PhD candidate at the University of Bamberg Germany. He holds a M.Sc. from the University of Bamberg in Business Administration. His research interests are in the fields of innovation management in the energy industry, customer-driven innovation, green innovation and sustainability. He also currently serves as an Innovation Manager for a Top 10 German municipal utility.

Dominik Dellermann is a Research assistant at the Chair for Information Systems (Prof. Dr. Jan Marco Leimeister) at the Research Center for Information System Design (ITeG) at the University of Kassel. His research interests are in the fields of IT innovation management, Crowdsourcing and entrepreneurship. 